\title{
O contexto de produção e as fotografias nos arquivos pessoais: um estudo nos artigos de periódicos da Ciência da Informação e Arquivologia
}

\author{
The context of production and photographs in personal archives: a study in the articles of \\ Information Science and Archival Science journals
}

\begin{abstract}
Anna Carla Almeida Mariz
Doutora em Ciência da Informação pelo IBICT e Universidade Federal do Rio de Janeiro - UFRJ, Brasil. Professora titular da Universidade Federal do Estado do Rio de Janeiro - UNIRIO, Brasil.
\end{abstract}

E-mail: annacarla@unirio.br

\author{
Rosa Inês de Novais Cordeiro \\ Doutora em Comunicação e Cultura pela Universidade Federal do Rio de Janeiro - UFRJ, Brasil. \\ Professora titular da Universidade Federal Fluminense - UFF, Brasil. \\ E-mail: rosanovais@id.uff.br
}

\section{Resumo}

Estudo resultante de uma pesquisa bibliográfica sobre arquivos pessoais, nos quais normalmente são encontrados documentos de gêneros diversos. Entre eles, com muita frequência, estão as fotografias, o que evidencia a importância desses acervos para a memória individual e familiar. São as características conhecidas como organicidade e autenticidade que qualificam os arquivos pessoais e suas fotografias como tais e os diferem das coleções. Este trabalho tem como objetivo verificar como são abordados esses acervos na literatura, de língua portuguesa, em artigos de periódicos, com destaque para os estudos sobre a questão do contexto de produção das fotografias, nos arquivos pessoais, e a observância desses registros visuais, a partir das seguintes categorias de análise: enfoque do tema, campo empírico e resultados. O tratamento técnico desses documentos apresenta especificidades, e cumpre examinar se a literatura da área vem registrando essas mudanças, quanto aos aspectos teóricos e empíricos de organização, e no que se refere ao crescimento desses acervos em quantidade e importância. Para tanto, foi realizada uma pesquisa bibliográfica, na literatura em língua portuguesa, em artigos de periódicos das áreas da Ciência da Informação e da Arquivologia, com uma abordagem quanti-qualitativa e observância às categorias de análise. Constata-se que, da mesma forma que a literatura sobre acervos fotográficos pouco evidencia os arquivos pessoais, o inverso também acontece: a literatura sobre arquivos pessoais pouco ressalta os documentos fotográficos, um gênero documental encontrado com muita frequência nos acervos pessoais e familiares. São dois temas que têm relação, porém a literatura que contemple o diálogo entre eles é muito escassa, especialmente no recorte escolhido.

Palavras-chave: Arquivo fotográfico. Arquivo pessoal. Arquivo pessoal - Fotografias.

\begin{abstract}
The following study is the result of a bibliographic research on personal archives in which documents of different genres are usually found. We often find photographs among them, confirming thus the importance of these archives for individual and family memory. Organicity and authenticity are characteristics that qualify personal archives and their photographs as such and what differ them from collections. This paper aims to verify how these archives are approached in the Portuguese language literature articles of journals, with emphasis on the study of the issue of production context of photographs in personal archives, and the analysis of photographs, based on the following examination categories: theme approach, empirical field and results. It should be noted that the technical treatment of these documents presents specificities, and it is necessary to examine whether the area literature has registered these changes regarding the theoretical and empirical aspects of organization and with regard to the growth of these documents in quantity and importance. Therefore, a review of the literature in Portuguese language were carried out in papers among journals in the areas of Information Science and Archival Science, with quantitative-qualitative approach and observing the analysis categories. It is observed that just as the literature on photographic documents hardly mentions the personal archives, the opposite also happens: the literature on personal archives hardly mentions photographic documents, a documental genre found very often in personal and family archives. Both themes are related, but the literature considering the dialogue between them is very rare, especially in the chosen approach.
\end{abstract}

Keywords: Photographic archives. Personal archives. Personal archives - Photographs.

InCID: R. Ci. Inf. e Doc., Ribeirão Preto, v. 12, n. 2, p. 194-217, set. 2021./fev. 2022. 


\section{Introdução}

Estamos vivendo em uma época em que praticamente não existem arquivos pessoais sem fotografias, e isso já é uma realidade há algum tempo. Os acervos contêm minimamente fotos do titular, às vezes em diferentes fases da vida, em alguns casos fotos de familiares, ou do titular com familiares. Podem conter fotografias relacionadas com a vida profissional do titular, de viagens, de eventos dos quais ele participou, entre tantos outros exemplos. Paulatinamente, as técnicas, os materiais e a tecnologia utilizados foram se aperfeiçoando e se sucedendo, e, em consequência, o uso e o alcance da fotografia também se modificaram. Essa realidade vem se transformando ainda mais. O que anteriormente era encontrado em menor quantidade em relação aos documentos textuais, vem se ampliando. Devido à facilidade cada vez maior de produzir e armazenar fotografias, os acervos estão aumentando muito no que diz respeito a esse gênero documental. Se considerarmos apenas as fotografias em papel, a quantidade presente em acervos já era significativa em meados do século XX. Mas, se levarmos em consideração também as digitais, as fotografias passaram a ser produzidas em torno do início do século XXI e, desde então, esse tipo de acervo aumentou de forma exponencial.

Essas mudanças, no que tange à relevância das fotografias nesses arquivos, vêm sendo acompanhadas de forma muito tímida pela literatura da área examinada, não refletindo tal realidade. Encontra-se literatura a respeito de arquivos pessoais em seus diversos aspectos. Uma abordagem recorrente é a institucionalização desses acervos, a passagem da custódia do próprio titular, ou da sua família, para alguma instituição que se ocupará da sua guarda, incluindo a organização e as providências para o acesso, sua abertura ao público. Entretanto, os textos analisados raramente abordam o tratamento técnico das fotografias existentes nos arquivos pessoais. Alguns autores apenas mencionam que fotografias foram encontradas nos acervos, outros chegam a quantificar, mas poucos se reportam ao tratamento técnico dispensado às fotografias nos arquivos pessoais.

Em 2018, realizou-se uma revisão de literatura (MARIZ; CORDEIRO, 2018) sobre fotografias nos arquivos, em que foi constatada escassa bibliografia sobre o assunto, bem como a ausência de enfoque referente aos atuais desafios enfrentados no tratamento arquivísticos das fotografias.

Neste artigo, o objeto de estudo continua sendo as fotografias, mas no âmbito dos arquivos pessoais. Portanto, este trabalho tem como propósito verificar como são enfocados 

periódicos da Ciência da Informação e Arquivologia

esses acervos na literatura publicada, em língua portuguesa, de artigos indexados na Base de Dados Referenciais de Artigos e Periódicos em Ciência da Informação (Brapci). Para isso, examinou-se, nos textos, a abordagem dos autores quanto ao contexto de produção das fotografias nos arquivos pessoais, e foram consideradas as seguintes categorias de análise: enfoque do tema, campo empírico e resultados. Destaca-se que o tratamento técnico desses documentos apresenta especificidades e cumpre examinar se a literatura da área vem registrando essas mudanças quanto aos aspectos teóricos e empíricos de organização e no que se refere ao crescimento desses acervos em quantidade e em importância ${ }^{1}$.

\section{Procedimentos metodológicos}

Este estudo foi desenvolvido a partir de pesquisa bibliográfica realizada em periódicos das áreas da Arquivologia e Ciência da Informação, em especial, os títulos cujos artigos enfocam assuntos no âmbito dos arquivos pessoais recuperados por meio de busca na base de dados Brapci $^{2}$, realizada em dezembro de 2018. Examinaram-se os documentos fotográficos em acervos pessoais, por meio de artigos de periódicos das áreas da Ciência da Informação e Arquivologia, no período de 1978 até 2018, em uma abordagem quanti-qualitativa. Conforme já mencionado, os textos foram mapeados, verificando-se o contexto de produção das fotografias nos arquivos pessoais e a pertinência do conteúdo dos artigos nas seguintes categorias de análise: enfoque do tema, campo empírico e resultados alcançados. Diante disso, os títulos de periódicos com maior recorrência ao tema da pesquisa foram: Ponto de Acesso, Ágora, Acervo, Arquivo \& Administração (A\&A), Estudos Históricos, Páginas A\&B e outros, com menos frequência.

\footnotetext{
${ }^{1}$ Este trabalho é parte integrante de pesquisa de pós-doutorado em Ciência da Informação no PPGCI da UFF.

2 A Base de Dados Referenciais de Artigos de Periódicos em Ciência da Informação (Brapci) atualmente disponibiliza 19.255 textos publicados, em 57 periódicos nacionais impressos e eletrônicos da área de Ciência da Informação (Biblioteconomia e Arquivologia). Estão indexados na Brapci artigos publicados nas revistas científicas e profissionais das áreas desde 1972 até o momento atual. Dos periódicos disponíveis, 40 estão ativos e 17 são históricos (descontinuados). Disponível em: https://www.brapci.inf.br/index.php/res/about. Acesso em: 25 mar. 2020. Também indexa publicações de Portugal, Peru, México, Cuba, Costa Rica, Espanha, Argentina e Colômbia. Disponível em: https://brapci.inf.br/index.php/res/about. Acesso em: 28 jan. 2021.

Apesar de se referir a "artigos publicados em revistas científicas e profissionais", na lista de coleções indexadas aparecem 'Eventos', quais sejam: Encontro Brasileiro de Bibliometria e Cientometria, Encontro Nacional de Pesquisa em Ciência da Informação e ISKO Brasil. Disponível em: https://www.brapci.inf.br/index.php/res/collections. Acesso em: 28 jan. 2021.
} 

periódicos da Ciência da Informação e Arquivologia

Como indicado na primeira parte da pesquisa, o objetivo era identificar, na bibliografia sobre arquivos fotográficos, como os autores enfocavam a importância do contexto de produção e do arquivo pessoal em relação aos registros fotográficos (MARIZ; CORDEIRO, 2018). Nesta segunda parte, o objetivo é detectar na literatura sobre arquivos pessoais, a importância do contexto de produção e como a fotografia é abordada. Assim, os termos escolhidos para a busca foram em torno de arquivos pessoais, dentro destes, a partir da análise, chegou-se às fotografias e ao contexto de produção.

Em consequência da busca realizada, os resultados assim se configuraram: para o assunto arquivo pessoal, foram obtidos 60 resultados. Contudo, a palavra-chave "arquivo pessoal", entre aspas, obteve 46 resultados e todos os resultados desta segunda busca constavam também da primeira. Em uma terceira busca, a palavra-chave "arquivo pessoa" recuperou 16 resultados, a maioria (94\%) era redundante ou não atendia aos critérios predefinidos. Apenas um artigo mostrou-se relevante e não constava das listas resultantes das buscas anteriores. Considerando que o mecanismo de busca não reconhece plurais, não houve diferença entre uma tentativa de busca das expressões "arquivo pessoal" e "arquivos pessoais". Após a comparação dos três resultados, verificou-se que a lista de 60 artigos incluía todos os outros, com exceção de um. Desses 61 artigos, consideraram-se 45. Os demais foram desconsiderados após a leitura do título e o resumo, por não abordarem o assunto investigado neste trabalho.

Deve-se mencionar que a revista A\&A é arrolada na base dados Brapci a partir de 2008. Diante disso, foi necessário realizar a busca na revista e incluir no corpus da análise seis artigos anteriores a 2008, devido à sua relevância temática para o estudo. Incorporou-se também na amostra o número especial da revista Estudos Históricos, do Centro de Pesquisa e Documentação de História Contemporânea do Brasil (CPDOC), dada à sua importância, por ser um número específico sobre arquivos pessoais, publicado em 1998 e resultante das conferências de um evento internacional - Seminário Internacional sobre Arquivos Pessoais — realizado no Brasil em 1997. Com o propósito de discutir os arquivos pessoais, contou com a participação de estudiosos do assunto, entre brasileiros e convidados de outros países. O evento marcou o início do aprofundamento das discussões sobre o assunto no Brasil. Este número especial tem 14 artigos. Então, ao todo, a amostra para este trabalho se constituiu de 45 artigos da base dados Brapci, seis artigos da revista A\&A e 14 artigos da revista Estudos Históricos. Totalizando 65 artigos, dentre os 80 levantados. 
Quadro 1 - Artigos considerados para a amostra

\begin{tabular}{|c|c|}
\hline Fonte & Número de artigos \\
\hline Base Brapci & 45 \\
\hline Revista A \& A & 6 \\
\hline Revista Estudos Históricos v.11, n.21, 1998 & 14 \\
\hline Total & 65 \\
\hline
\end{tabular}

Fonte: Elaborado pelas autoras com base na análise quantitativa (2021).

O mapeamento dos artigos deu-se a partir das categorias citadas, e examinou-se também o contexto de produção das fotografias nos arquivos pessoais. Apesar de atualmente existir na área da Arquivologia um número crescente de produção bibliográfica sob a forma de livros, especialmente sobre arquivos pessoais, optou-se por não os incluir, uma vez que o recorte deste trabalho foi a revisão dos periódicos científicos.

Em face do exposto, optou-se neste estudo, como recurso metodológico, com base na literatura levantada, por selecionar autores que pudessem nos auxiliar a introduzir o enfoque sobre a presença de fotografias em arquivos pessoais e, a seguir, elegeu-se o referencial teórico para aprofundar a discussão quanto ao contexto de produção das fotografias para a organização de acervos, nos arquivos pessoais.

\section{O lugar dos arquivos pessoais na literatura}

As pesquisas sobre os arquivos pessoais e a sua inserção nos estudos teóricos da Arquivologia se deram tardiamente, por não terem sido sempre consideradas como parte dos arquivos, ou seja, das organizações arquivísticas. Os estudiosos da teoria arquivística tinham os arquivos públicos como centro das atenções. Os estudos voltados para os arquivos pessoais não eram muito comuns, nem numerosos. Na literatura, aponta-se essa lacuna.

Em evento realizado em 1997, há quase 25 anos, Heloisa Bellotto salientava a posição dos arquivos pessoais à margem dos estudos dedicados à Arquivologia. Mas, naquele momento, indicava mudanças nesse panorama, apontando como um dos indicadores a realização do Seminário Internacional sobre Arquivos Pessoais, que foi fundamental para o estudo dos arquivos pessoais no país. O Seminário reuniu pesquisadores brasileiros e internacionais com o objetivo de apresentar e discutir teoria e práticas em arquivos pessoais. 
Interdisciplinares por excelência, dando motivos a infinitas abordagens e olhares, os arquivos pessoais não tinham merecido, até duas ou três décadas atrás, a devida atenção no que diz respeito à sua existência, rastreamento, poderiam e deveriam ser. Hoje a situação é bem outra. Com os arquivos pessoais inspirando e documentando trabalhos acadêmicos e de ficção (literatura e cinema), dando origem a exposições e motivando a publicação de instrumentos de pesquisa, assim como a realização de um seminário do porte deste, estão demonstradas a dinamização e o crescimento dos recolhimentos, da organização e da disponibilização dos documentos de origem privada em entidades especializadas públicas ou particulares (BELLOTTO, 1998, p. 202).

Outro aspecto, que envolve consenso na área, diz respeito à constatação de que os arquivos pessoais ficaram relegados a segundo plano nos estudos arquivísticos, em relação aos arquivos institucionais. Contudo, Terry Cook (1998), no mesmo Seminário, aponta duas similaridades importantes entre os arquivos pessoais e os públicos:

Primeiro, ambos são artefatos de registro derivados de uma atividade; os arquivos são evidências das transações da vida humana, seja ela organizacional, e por conseguinte oficial, seja individual, e portanto pessoal, mas surgem, antes, dentro de um contexto, como parte de alguma outra atividade ou necessidade, seja pessoal, seja institucional. Em segundo lugar, os arquivistas, tanto nos arquivos públicos quanto nos pessoais, frequientemente [sic] usam procedimentos técnicos e métodos práticos semelhantes, em termos de como acessam, descrevem, armazenam fisicamente e conservam os arquivos e os colocam à disposição para fins de pesquisa. (COOK, 1998, p. 131)

Na opinião de Thomassen (2012), os arquivos pessoais são movidos da periferia para o centro do discurso arquivístico, pois há uma tensão entre os esforços pouco eficazes para documentar a sociedade como um todo e o poder de autodocumentação da própria sociedade.

Oliveira (2013) também menciona o assunto, afirmando que os arquivos pessoais foram os "estranhos" da Arquivologia por muito tempo, passando a ser um problema de pesquisa e objeto de reflexão, na literatura da área, apenas a partir de meados do século XX.

Alguns autores, entre eles, Camargo (2008), ponderam sobre os acervos pessoais terem sido tratados comumente por práticas biblioteconômicas e não arquivísticas, e algumas dessas práticas resultaram no distanciamento da aplicação dos princípios arquivísticos na organização. Sobral e Macêdo (2017), por exemplo, asseveram que os arquivos pessoais, sob a custódia das divisões de manuscritos das bibliotecas, eram organizados como coleções. Desse modo, a responsabilidade adquirida pelas bibliotecas em custodiar os arquivos pessoais gerou impactos no tratamento desses acervos. Essa condição estabelecida historicamente manteve-se por longo tempo, já que a primeira definição para arquivos pessoais só apareceu em um manual, no ano de 1928, o de Casanova.

Somente a partir da segunda metade do século XIX, segundo Fraiz (1998), o arranjo de documentos pessoais deixou de se basear em práticas e métodos biblioteconômicos. 

periódicos da Ciência da Informação e Arquivologia

Anteriormente não se levava em consideração seu caráter orgânico, perceptível pelo processo de acumulação. Eram considerados como unidades avulsas. A autora afirma, baseada em Schellenberg (1973), que se deve aplicar aos arquivos pessoais os mesmos princípios de proveniência e do respeito à ordem original, adotados no arranjo de documentos em arquivos públicos.

Os arquivos pessoais vêm ganhando importância, o que pode ser visto por meio de um maior número de profissionais se dedicando ao assunto, tanto no que diz respeito a estudos teóricos, quanto à atuação prática de publicações sobre o tema, e ainda de instituições se dedicando a receber e tratar esses acervos.

Sobre o que são os arquivos pessoais, Oliveira (2008, p. 38) assim define:

Entendemos os arquivos pessoais como o conjunto de documentos produzidos ou recebidos, e mantidos por pessoa física ao longo de sua vida e em decorrência de suas atividades e função social. Desse modo, são evidências de uma pessoa e de seu papel na sociedade, em um sentido mais amplo.

A autora pontua as diferenças entre os arquivos institucionais:

Diferente dos arquivos corporativos, os arquivos pessoais trazem em si elementos de traços da personalidade, de juízos de valor, preconceitos, anseios, opiniões sobre assuntos diversos que expressam os interesses e atividades dos produtores dos arquivos e das pessoas com as quais se relacionaram. O potencial de informação dos arquivos pessoais é enorme. (OLIVEIRA, 2008, p. 39)

Na visão de Sobral e Macêdo (2017, p. 104), um arquivo pessoal é criado por um indivíduo para organizar sua vida em sociedade e, assim, invariavelmente, apresenta seus afetos, desafetos e expressões de sentimentos. Sua "complexidade encontra-se justamente no fato do indivíduo desempenhar diversas atividades no decurso de sua vida, e a produção documental decorrente não estar determinada por normas institucionais, bem como a sua acumulação e/ou descarte".

Porém Heymann (1997) lembra que os arquivos pessoais não são exatamente os espelhos das trajetórias de vida dos seus titulares, pois as escolhas são intencionais, e os conjuntos estão sujeitos a processos de seleção e reordenamento interno. Esse é um tema recorrente, apontado na literatura: a seleção feita por familiares ou pela pessoa que vai fazer a intermediação com a instituição, ao passar a custódia do arquivo, do âmbito familiar para o institucional. Nem sempre o arquivo chega à instituição como foi originariamente acumulado, passa por intervenções que podem suprimir partes e/ou interferir na ordem original. 
Terry Cook (1998) explica que, no Canadá, os arquivos pessoais são vistos como complemento e suplemento dos fundos de arquivos oficiais ou públicos:

[...] a tradição dos 'arquivos totais' canadenses está mais voltada para os arquivos de governança que para os arquivos de governo. Arquivos 'de governança' incluem os documentos que refletem a interação dos cidadãos com o Estado, o impacto do Estado sobre a sociedade e as funções ou atividades da própria sociedade, tanto quanto incluem os documentos das estruturas do governo e de seus burocratas voltados para dentro. A tarefa arquivística coletiva no Canadá é preservar a evidência documentada da governança da sociedade, não apenas da atividade governante dos governos (COOK, 1998, p. 143).

\section{Resultados e discussão}

Como já dito, a busca na base de dados Brapci abrangeu o período de 2008 a 2018, e incluíram-se também os artigos das revistas Arquivo \& Administração e Estudos Históricos, entre 1978 e 2004, obtendo-se baixa frequência de resultados. A exceção é o ano de 1998, que apresenta 15 artigos, devido ao número especial da revista Estudos Históricos, e mais a ocorrência de um artigo da A\&A. Sem considerar essa frequência atípica, verifica-se que a quantidade dos artigos publicados tem crescido, com o passar dos anos.

Tabela 1 - Número de artigos publicados no tema por ano

\begin{tabular}{|c|c|c|c|}
\hline Ano & $\begin{array}{l}\text { Número } \\
\text { de artigos }\end{array}$ & Ano & $\begin{array}{l}\text { Número } \\
\text { de artigos }\end{array}$ \\
\hline 1978 & 1 & 2012 & 2 \\
\hline 1986 & 1 & 2013 & 7 \\
\hline 1998 & 15 & 2014 & 5 \\
\hline 2004 & 1 & 2015 & 3 \\
\hline 2008 & 4 & 2016 & 4 \\
\hline 2010 & 2 & 2017 & 7 \\
\hline 2011 & 2 & 2018 & 11 \\
\hline
\end{tabular}

Fonte: Elaborado pelas autoras com base na análise quantitativa (2021).

Até 2010, a frequência ainda é irregular, não aparecem artigos em todos os anos. A partir de 2010, surgem textos em todos os anos. De 1978 a 2010, são 24 artigos e, de 2011 a 2018, são 41, o que deixa claro o crescente interesse e o aumento das pesquisas e da produção bibliográfica sobre o assunto. 
Dos 65 textos, 26 (40\%) tratam dos arquivos pessoais, utilizando algum acervo como fonte para análise ou como estudo de caso. Destes 26, em 17 (65\%), está explícito o campo empírico no título do artigo. Entre os 26 que observam algum acervo, temos 4, em 1998; um, em 2008; em 2010, são 2; em 2013, são 3; 2014 tem 1; 2015, são 3; 2016, são 2; 2017, são 4; e 2018, são 6. Como tendência do estudo empírico, nos primeiros anos em que são publicados, tais artigos (1998 e 2008) situam-se na casa dos 25\%; em dois anos (2010 e 2015), chegam a 100\%; e nos últimos anos (2016, 2017 e 2018), se mantém entre 50\% e 60\%, do total pesquisado.

Tabela 2 - Distribuição por ano e porcentagem dos artigos que utilizam algum acervo pessoal

\begin{tabular}{c|c|c|c|c|c|c|c}
\hline Ano & $\begin{array}{c}\text { Total de } \\
\text { textos } \\
\text { que } \\
\text { tratam } \\
\text { de } \\
\text { arquivos } \\
\text { pessoais }\end{array}$ & $\begin{array}{c}\text { Total de } \\
\text { textos } \\
\text { referentes } \\
\text { a um } \\
\text { arquivo } \\
\text { pessoal } \\
\text { específico }\end{array}$ & Porcentagem & Ano & $\begin{array}{c}\text { Total de } \\
\text { textos } \\
\text { que } \\
\text { tratam de } \\
\text { arquivos } \\
\text { pessoais }\end{array}$ & $\begin{array}{c}\text { Total de } \\
\text { textos } \\
\text { referentes } \\
\text { a um } \\
\text { arquivo } \\
\text { pessoal } \\
\text { específico }\end{array}$ & Porcentagem \\
\hline 1998 & 15 & 4 & $25 \%$ & 2015 & 3 & 3 & $100 \%$ \\
\hline 2008 & 4 & 1 & $25 \%$ & 2016 & 4 & 2 & $50 \%$ \\
\hline 2010 & 2 & 2 & $100 \%$ & 2017 & 7 & 4 & $58 \%$ \\
\hline 2013 & 7 & 3 & $43 \%$ & 2018 & 11 & 6 & $55 \%$ \\
\hline 2014 & 5 & 1 & & & & & \\
\hline
\end{tabular}

Fonte: Elaborado pelas autoras com base na análise quantitativa (2021).

A seguir, os resultados alcançados referentes ao contexto de produção das fotografias nos arquivos pessoais. A pertinência do conteúdo dos artigos é apresentada em duas subseções.

\subsection{As relações entre o contexto de produção dos documentos e os arquivos pessoais}

O contexto de produção, entendido como o ambiente e as circunstâncias em que ocorre a ação de geração dos documentos, é de crucial importância para os arquivos. A relação orgânica que os documentos de arquivo apresentam entre si é, talvez, a sua principal característica. Não é algo que seja importante apenas no que se refere aos arquivos pessoais, ou aos documentos fotográficos, mas de fundamental importância para os documentos arquivísticos como um todo. No entanto, é necessário que isso seja explicitado, é importante que seja estudado e dito, e não fique apenas no plano do implícito. As delimitações de um campo de estudo necessitam ser postas claramente.

Como foi visto em relação aos documentos fotográficos, também é possível encontrar textos sobre arquivos pessoais que abordam a importância do contexto de produção para o 

periódicos da Ciência da Informação e Arquivologia

tratamento dos arquivos pessoais. Entre os textos analisados sobre arquivos pessoais, alguns abordam de forma evidente este aspecto, e apresentam a questão da seguinte forma:

Na visão de Camargo (2008, p. 6) para arquivos de uma maneira geral, a abordagem contextual reconhece o

[...] arquivo como um todo articulado, resultante de determinadas injunções, com partes interdependentes, sejam os documentos originários do funcionamento de instituições (públicas ou privadas) ou acumulados por pessoas físicas. Cada parte só tem sentido se associada às demais, razão por que, no arquivo, a organicidade é um atributo essencial. Em outras palavras: o conjunto de documentos a que chamamos arquivo depende das condições que, por sua integridade e maneira de organização, lhe permitem refletir a entidade produtora.

Com o foco nos arquivos pessoais, Abreu (2016) considera que, para qualquer análise ou processamento, é fundamental partir de uma abordagem contextual

[...] na qual o arquivo pessoal é encarado como um organismo com partes interrelacionadas e pelo qual as funções e atividades do titular são reconhecidas. Sem a nitidez do contexto, não há garantia de autenticidade, e sem essa característica, a existência enquanto documento de arquivo está comprometida (ABREU, 2016, p. 141).

Sobral e Macêdo (2017) também concordam que é essencial, para o tratamento documental de arquivos pessoais, entender o contexto em que o produtor se insere no momento da produção, pois esse conhecimento da trajetória do produtor, seus meios de inserção e suas motivações são capazes de oferecer indícios, ao arquivista, sobre qual metodologia utilizar nesse processo, qual tipo de arranjo adotar e até mesmo de que forma descrever o acervo em questão. Por isso, julgam que o trabalho de pesquisa em arquivos pessoais deve considerar os múltiplos contextos que compõem a gênese documental, e que isso, consequentemente, vai contribuir para a construção do contexto arquivístico.

Tognoli e Barros (2011) avaliam que, no caso dos arquivos pessoais, a acumulação e os documentos ali encontrados têm características muito particulares ligadas à vida do titular e, no caso de escritores/artistas, à sua obra. Dessa forma, afirmam que a descrição, organização e demais fases do tratamento arquivístico devem levar em conta todas as informações contextuais possíveis e, além de todas as ferramentas tradicionais que o arquivista possui, deve-se trabalhar com um elemento a mais: a produção intelectual e a vida do titular do arquivo.

Terry Cook (1998) ressalta que deve ser valorizado o contexto por trás do texto, já que 

periódicos da Ciência da Informação e Arquivologia

[...] as relações de poder que conformam a herança documental lhe dizem tanto, se não mais, que o próprio assunto que é o conteúdo do texto. Nada é neutro. Nada é imparcial. Tudo é conformado, apresentado, representado, simbolizado, significado, assinado, por aquele que fala, fotografa, escreve, ou pelo burocrata governamental, com um propósito definido, dirigido a uma determinada audiência (COOK, 1998, p. 139-140).

Camargo (2008), entre outros autores, indaga como poderíamos alijar do arquivo documentos pelas suas características formais, por serem de determinados formatos (livros) ou por suas técnicas de registro (impressos), ou por suportes inusitados (das honrarias, por exemplo), sem comprometer a organicidade do conjunto. Esta autora (2008, p. 6) afirma que a teoria arquivística abre mão de aspectos materiais "em favor da instrumentalidade que assumem os documentos dentro de contextos específicos", e as fotografias podem ser um exemplo disto.

Ducrot (1998) defende a importância do contexto nos arquivos pessoais:

[...] tirar os documentos do conjunto original a que pertenciam, ou romper sua ordem inicial no seio do fundo para distribuí-los entre temas arbitrariamente escolhidos e que, na maioria das vezes, deixavam de fazer justiça à sua riqueza (já que cada documento pode responder a várias questões), tornava inviável qualquer pesquisa. (DUCROT, 1998, p. 154)

O impacto de se observar o contexto de produção para a organização dos acervos é também tratado por autores que se dedicam a estudar os arquivos pessoais. Dentre esses, Sobral e Macêdo (2017) advertem que a descrição e o tratamento da informação de documentos pessoais apresentam um grau maior de dificuldade, "relacionada em grande medida ao contexto de produção, ao uso e à guarda que perpassam a história do fundo. E agravada, em geral, pela escolha de termos e o uso da normatização em detrimento da especificidade do acervo" (SOBRAL; MACÊDO, 2017, p.103).

Camargo (2008) atribui ao arquivista a responsabilidade de restabelecer o vínculo entre a atividade e o documento que a viabilizou ou registrou, e reconhece que a tarefa é dificultada, no âmbito dos arquivos pessoais

[...] pela ausência de certos instrumentos de que dispõem as organizações para dividir responsabilidades no cumprimento de suas finalidades: estatutos, regulamentos, organogramas etc. Quando se trata de pessoas, nem mesmo o memorial acadêmico e o currículo pormenorizado logram fornecer a chave classificatória com que pretendemos contextualizar os documentos de seus arquivos (CAMARGO, 2008, p. 9).

Visando reduzir esses obstáculos, Oliveira (2013) acredita que devem ser produzidos, minimamente: 
relevantes para a compreensão de seu lugar social e de seus relacionamentos, e histórias administrativas das instituições onde atuou, com especial destaque para o período em que ocupou alguma função (OLIVEIRA, 2013, p. 44).

Silva (2013) complementa sobre os caminhos a serem percorridos para lograr êxito ao organizar arquivos pessoais:

\begin{abstract}
O levantamento da tipologia documental em arquivos institucionais leva o arquivista a estudar as funções do órgão produtor e as atividades relacionadas a essas funções, para se chegar à produção documental oriunda de cada atividade. Nos arquivos pessoais, o desafio maior seria o de definir o que poderia ser considerado 'função' de uma pessoa. Mais apropriado seria trabalhar com as 'atividades' desempenhadas por uma pessoa durante sua vida. Assim, o estudo da biografia de uma pessoa torna-se fundamental, antes da etapa de identificação e descrição dos documentos. Conhecendo toda a trajetória de vida da pessoa, o arquivista poderá mais facilmente identificar os documentos e relacioná-los às atividades que o produziram. Esse caminho torna-se mais seguro e de melhor aplicabilidade (SILVA, 2013, p. 165).
\end{abstract}

Nos arquivos pessoais, são encontrados documentos que normalmente não fazem parte de arquivos institucionais, essa é uma das particularidades desses acervos. Camargo (2008) considera que o fato de haver neles um grande número de itens desprovido de metadados é um dos elementos que faz com que os arquivos pessoais não sejam especialmente considerados dentro da literatura arquivística. Por exemplo, a autora cita o caso das fotografias e recortes de jornais, que quase nunca ostentam as necessárias referências tópicas e crônicas, obrigando o profissional a um esforço redobrado na tarefa de contextualização. Mas observa que, apesar disso, sempre que for possível recompor a trajetória do titular a partir dos documentos por ele acumulados, o arquivo é dotado de organicidade, tanto quanto os que resultam do funcionamento de instituições:

E a capacidade reflexiva que reconhecemos em tais conjuntos documentais, permitindo conhecer as atividades que lhes deram origem, é base do principal atributo dos arquivos - a autenticidade que independe de formalidades e sinais de validação. Se nos arquivos pessoais encontramos meios inusitados de registro, não nos impedem eles de reconhecer sua funcionalidade e, portanto, seu contexto de produção (CAMARGO, 2008, p. 8).

Silva (2004) expõe também sobre ser “inevitável encontrar uma tipologia documental diversificadíssima" nos arquivos pessoais e, entre as citadas, menciona as fotografias, acrescentando "que faz parte de um único e polifacetado sistema" (SILVA, 2004, p. 36).

Santos (2008b) acrescenta que a forma física e de registro das informações pessoais são bastante diversas e cita, como as mais comuns, alguns gêneros: textual, representado por correspondências, relatórios, certificados, livros, cartões, entre outros; o cartográfico e iconográfico, tais como fotografias, mapas, cartazes, entre outros; o filmográfico e o sonoro, caracterizados por fitas de videocassete e fitas cassete de áudio; e a documentação digital, em 

periódicos da Ciência da Informação e Arquivologia

todas as suas possibilidades, incluindo e-mails, downloads, extratos bancários, bases de dados, gravações pessoais em DVD, entre outros (SANTOS, 2008b, p. 65).

Ducrot (1998, p.157) salienta que além dos documentos escritos do tipo tradicional, podem pertencer a um fundo de arquivo, cartazes, mapas e plantas, desenhos e croquis, fotografias, gravações sonoras, visuais ou digitais, filmes, entre outros, "que nasceram como que automaticamente da atividade quotidiana de uma pessoa e que esclarecem ou completam os outros documentos que essa pessoa produziu no âmbito de sua atividade". Mas ressalta que, apesar de o formato ou suporte impedir de serem mantidos, fisicamente, junto a outros documentos do fundo, eles fazem parte de tal conjunto orgânico e "devem ser inseridos em seu lugar lógico no quadro de arranjo e no inventário." Ela lamenta a separação de documentos que provêm de uma mesma pessoa com base no tipo do material, como por exemplo livros, condecorações, uniformes, pois isso impediria de estudá-los de forma completa. E conclui afirmando que "o princípio da proveniência continua sendo a melhor garantia de uma classificação clara e eficaz para os arquivos pessoais e familiares, embora exija um refinamento de certos pontos que lhes são específicos" (DUCROT, 1998, p. 166-7).

Artieres (1998), em um texto clássico na área, cria uma situação hipotética, em que imagina um lugar onde poderíamos encontrar os registros de toda a nossa vida. Encontraríamos passagens de avião, tíquetes de metrô, listas de tarefas, notas de lavanderia, contracheques; encontraríamos também velhas fotos amarelecidas, cartas: correspondências administrativas e cartas apaixonadas, misturadas com cartões postais, ou ainda um telegrama urgente anunciando um nascimento, entre outras coisas. Contudo, o autor faz a ressalva de que as pessoas não podem guardar tudo, e fazem, por isso, uma seleção intencional.

Oliveira (2008) menciona a fala de Artieres e acrescenta novos documentos, derivados das atuais inovações tecnológicas:

[...] a contemporaneidade nos remete às novas formas de registro: as passagens aéreas se transformam em e-tickets, as cartas em e-mails, os postais em postais virtuais, os álbuns fotográficos em álbuns digitais, e, muitas vezes, visualizados no Orkut, em Blogs, e esses últimos também são utilizados como os antigos diários. Os convites para casamentos e outros eventos transformaram-se em convites virtuais, afinal a mala direta on-line é infindável e rapidamente atualizada, o imposto de renda já fazemos on-line, etc. (OLIVEIRA, 2008, p. 40)

A autora acrescenta que, atualmente, precisamos lidar com uma realidade híbrida, não apenas os documentos previstos por Artières (1998), nem apenas os gerados pelas tecnologias atuais, os acervos contêm documentos representativos de ambas as épocas, de convivência entre 

periódicos da Ciência da Informação e Arquivologia

as tecnologias mais tradicionais e seus meios de armazenamento e os novos processos tecnológicos e suas mídias.

Carvalho, Maia e Oliveira (2017) afirmam que "nos arquivos pessoais, é comum encontrarmos registros que representam o nascimento, as bodas, as grandes viagens e a morte, eventos marcantes na existência de um indivíduo. Os registros podem ser explícitos ou simbólicos" (CARVALHO; MAIA; OLIVEIRA, 2017, p. 63). Os eventos citados são tipos de situações em que comumente são produzidas fotografias, logo muitos registros, mencionados pelos autores, costumam ser documentos fotográficos. Podem ser também filmes, gravações sonoras, entre outros registros, mas frequentemente são fotografias, ou até mesmo vários registros em gêneros diferentes de um mesmo acontecimento.

Trancoso e Silva (2013) consideram os arquivos pessoais um grande desafio, imposto

[...] pela diversidade de documentos e de objetos acumulados pelo indivíduo por toda a vida, por ser a produção documental um produto subjetivo, individual, representação das atividades de uma pessoa e que, muitas vezes, chega à instituição de guarda de forma descontextualizada (TRANCOSO; SILVA, 2013, p. 58).

A diversidade de materiais encontrados nos arquivos pessoais pode estar ligada também à atividade profissional desenvolvida pelo titular do acervo. Alguns autores defendem a ideia de especificar a área de atuação do titular e se referir a elas, tais como: arquivos de cientistas, arquivos de escritores, arquivos de políticos, ao invés de simplesmente chamá-los de arquivos pessoais. Pois, de acordo com a(s) atividade(s) realizada(s) pelo titular, ao longo da vida, os tipos documentais encontrados no acervo serão muito diversos, exigindo uma organização que se adapte/se adeque à natureza do acervo.

Esses arquivos, principalmente de pessoas públicas, não preservam apenas as lembranças e a história do seu titular e sua família. Ali estão registrados acontecimentos e costumes sociais de uma época, uma região, uma comunidade, uma classe social. A preservação de arquivos pessoais, inevitavelmente, colabora para a preservação da memória social, colaborando, inclusive, para a construção do patrimônio cultural.

Sobral e Macêdo (2017) apresentam a análise da arquivista Laura Millar (2006) sobre a relação entre arquivos e memória, quando afirma que os arquivos que mantemos intencionalmente para lembrar de acontecimentos da vida podem auxiliar a lembrar e partilhar essa memória com os outros, articulando a memória coletiva com a individual. 

periódicos da Ciência da Informação e Arquivologia

Uma das expressões da memória, no âmbito familiar, é a existência de álbuns de fotografias. Vianna, Lissovsky e Sá (1986, p. 64) citam Bourdieu (1965), em relação às fotografias do álbum de família,

[...] evocam e transmitem a recordação dos acontecimentos que merecem ser conservados porque o grupo vê um fator de unificação nos movimentos da sua unidade passada ou, o que é equivalente, porque retém do seu passado as confirmações da sua unidade presente (BOURDIEU, 1965, p. 53-54) . $^{3}$

Os álbuns de família são objeto de estudo de alguns autores, que se dedicam a analisar, entre outras coisas, como se dá a sua elaboração e uso. Artières (1998) apresenta uma análise sobre o álbum de família:

Vejamos nesse sentido a prática do álbum de fotos de família, que Anne-Marie Garat estudou de maneira admirável. Em toda família, existe com efeito o hábito de dedicar regularmente longas tardes a reunir e a organizar as fotos relacionadas com a vida de cada um dos seus membros. Um casamento, um nascimento, uma viagem são objeto de uma ou de várias páginas. Não colamos qualquer foto nos nossos álbuns. Escolhemos as mais bonitas ou aquelas que julgamos mais significativas; jogamos fora aquelas em que alguém está fazendo careta, ou em que aparece uma figura anônima. E depois as ordenamos esforçando-nos para reconstituir uma narrativa. Quando a foto é muito enigmática, acrescentamos um comentário. Quando uma visita chega, começa a cerimônia das fotos, fazem-se observações, viram-se algumas páginas rapidamente. Acontece também, com o tempo, de algumas fotos serem retiradas, porque são comprometedoras, porque não são condizentes com a imagem que queremos dar de nós mesmos e da nossa família. Pois o álbum de retratos constitui a memória oficial da família; só raramente os amigos têm um lugar nele. O essencial é que em alguns minutos, uma hora no máximo, possamos justificar o tempo passado e a sua coerência. Sob esse ponto de vista, as páginas dedicadas às viagens são muito significativas. Exibimos provas mostrando, por exemplo, a família au grand complet diante de um monumento. No álbum, fazemos figurarem também os nossos antepassados; aí também trata-se de comprovar que pertencemos a uma linhagem, que temos raízes. Quando um antepassado é embaraçoso, ou porque ficou louco, ou porque teve uma atitude pouco apropriada, suprimimos sua presença: pintamos sua cara de preto ou retiramos sua foto. Se as ausências nos álbuns são toleradas, não manter arquivos fotográficos da família, em compensação, constitui uma falta. E um dever produzir lembranças; não fazê-lo é reconhecer um fracasso, é confessar a existência de segredos. O álbum é uma garantia de transparência, um passaporte de sinceridade e uma prova de ajustamento (ARTIERES, 1998, p. 14).

É interessante observar que algo que é representativo para uma pessoa, ou família, pode não ser para outra, e é justamente a observação do todo que preenche as lacunas da memória coletiva. Quanto mais arquivos pessoais preservados, maior a chance de recuperação e entendimento de uma certa realidade.

Por fim, sobre os álbuns de família, a fim de evidenciar esse registro e sua organização, menciona-se aqui o trabalho de Silva e Cordeiro (2016), em pesquisa que compara a

\footnotetext{
${ }^{3}$ BOURDIEU, Pierre. Un art moyen: essai sur les usages sociaux de la photographie. Paris, Minuit, 1965.
} 
organização, a descrição e a representação desses registros em diferentes unidades de memória e informação (arquivos, bibliotecas e museus), no Rio de Janeiro. Para tal estudo, as autoras ponderam que três obras foram de importância significativa para a compreensão da natureza desse objeto de estudo: Armando Silva (2008), Miriam Moreira Leite (2001) e Myriam Moraes Lins de Barros e Ilana Strozenberg (1992). A respeito da constituição dos álbuns de família, Silva e Cordeiro (2016) destacam que a fotografia é o elemento predominante, mas

[...] não são formados exclusivamente por fotografias; fazem parte desse documento outros tipos de objetos e itens, também visuais, que são anexados a ele, como mechas de cabelo, gotas de sangue, pedaços de unhas, folhas secas, cartões postais e recortes de jornais, entre outros, e os quais foram denominados por Silva (2008, p. 11, 18 e 64) como 'restos' das famílias. Para este autor, o álbum de família é um 'livro aberto, não só porque está disposto a receber o que vier no futuro, mas porque nele entram diferentes objetos, da mais variada natureza, que se mesclam às fotos' (SILVA; CORDEIRO, 2016, p. 883).

\subsection{As fotografias nos arquivos pessoais e a abordagem dos conteúdos nos artigos}

A partir do objetivo deste artigo, percebeu-se que a grande maioria dos textos não menciona as fotografias (77\%), e os que o fazem, em sua maior parte, apenas tangenciam o tema. Apesar dos baixos resultados, será apresentada aqui a discussão dos indicativos alcançados quanto ao tratamento arquivístico destinado aos documentos fotográficos, nos textos analisados. Cabe destacar que a pouca quantidade de artigos encontrados também é um indicador a ser considerado.

No que diz respeito ao contexto de produção dos documentos nos arquivos pessoais que mencionam o tratamento de fotografias, grande parte refere-se a relatos de casos sobre um determinado acervo e, na maioria das vezes, registra como se configura a documentação, quais e quantos são os documentos e, dentre esses, cita os documentos fotográficos e a sua quantificação, ou onde se encontram no arranjo. Alguns textos apenas referem-se a fotografia, quando relatam em que consiste o acervo, quantificação e gêneros encontrados, por exemplo.

Nos artigos que abordam os arquivos pessoais como campo empírico, quando analisam um arquivo específico, a menção às fotografias é mais frequente. Dentre os 65 textos analisados, 26 se dedicam a algum arquivo pessoal, e, destes 26, 11 citam a fotografia em algum grau de profundidade, ou seja, 43\%. Já entre os que não são direcionados a algum tipo de acervo, ou seja, os outros 39 textos, apenas 4 citam a fotografia (10\%). 

periódicos da Ciência da Informação e Arquivologia

Quadro 4 - Artigos sobre arquivos pessoais que mencionam fotografias

\begin{tabular}{c|c|c|c}
\hline Artigos sobre arquivos pessoais & $\mathrm{N}^{\circ}$ & $\begin{array}{c}\text { Número de artigos que citam } \\
\text { a fotografia em algum grau de } \\
\text { profundidade }\end{array}$ & Porcentagem \\
\hline $\begin{array}{c}\text { Artigos que tratam de algum acervo } \\
\text { específico }\end{array}$ & 26 & 11 & $43 \%$ \\
\hline $\begin{array}{c}\text { Artigos que não são direcionados a } \\
\text { algum acervo }\end{array}$ & 39 & 4 & $10 \%$ \\
\hline Total & 65 & 15 & $23 \%$ \\
\hline
\end{tabular}

Fonte: Elaborado pelas autoras com base na análise quantitativa (2021).

Só um artigo foi recuperado nas buscas efetuadas, na revisão de literatura realizada sobre arquivos fotográficos (MARIZ; CORDEIRO, 2018), e na revisão de literatura sobre arquivos pessoais deste trabalho. Refere-se ao texto intitulado "Arquivo Pessoal e Fotografias: Lugar de Construção Fotoaubiográfica", no qual as autoras apresentam como proposta de pesquisa "a análise da dimensão educacional do paraibano Afonso Pereira da Silva por meio da elaboração de sua fotoautobiografia, partindo das fotografias constantes em seu arquivo pessoal, enfocando sua ação de fundador da Universidade Federal da Paraíba (UFPB)" (GONÇALVES; ALBUQUERQUE, 2015, p. 52). No artigo, informam-se a proposta de pesquisa a ser realizada, a metodologia a ser utilizada, e as justificativas teóricas, nas quais destacam a importância da fotografia para a reconstituição da trajetória do titular do arquivo, em especial relacionando com a atividade exercida pelo retratado (que deu origem à universidade), como fonte de informação, fonte histórica e de memória.

Quadro 1 - Categoria de análise - enfoque do tema (continua...)

\begin{tabular}{|c|c|}
\hline $\begin{array}{c}\text { Autor(es), Título e periódico, } \\
\text { Ano }\end{array}$ & $\begin{array}{c}\text { Como fotografias são abordadas nos artigos } \\
\text { examinados }\end{array}$ \\
\hline $\begin{array}{l}\text { GOMES, Michele de Almeida; } \\
\text { SILVA, Maria Celina Soares de } \\
\text { Mello e. } \\
\text { Objetos tridimensionais em } \\
\text { arquivos pessoais de cientistas. } \\
\text { Arq. \& Adm., Rio de Janeiro, } \\
\text { v.10, n.1, jan./jun. } 2011 .\end{array}$ & $\begin{array}{l}\text { Gomes e Silva, tratando de arquivos pessoais de } \\
\text { cientistas, baseiam-se em Camargo para afirmar que o } \\
\text { "gênero documental pode ser também definido por } \\
\text { sistemas de signos (linguagens) designados por três tipos } \\
\text { representados: a palavra escrita, a imagem e o som" (p. } \\
\text { 35) }\end{array}$ \\
\hline $\begin{array}{l}\text { CALLIGARIS, Contardo. } \\
\text { Verdades de autobiografias e } \\
\text { diários íntimos. } \\
\text { Estudos Históricos, n. } 21,1998 \text {. }\end{array}$ & $\begin{array}{l}\text { O artigo de Calligaris }(1998, \text { p. } 46) \text { menciona fotografias } \\
\text { quando cita a "memória material: desde as fotos de } \\
\text { lembrança, até a simples acumulação de objetos e } \\
\text { documentos" complementando que "esses conjuntos, às } \\
\text { vezes confusos, outras vezes ordenados e organizados, } \\
\text { reunidos ou não com o intento de constituir um arquivo, } \\
\text { se transformam inevitavelmente em arquivos pessoais" }\end{array}$ \\
\hline
\end{tabular}




\begin{tabular}{|c|c|}
\hline $\begin{array}{l}\text { SANTOS, Paulo Roberto Elian. } \\
\text { A ciência, os cientistas e os seus } \\
\text { arquivos. } \\
\text { Arquivo \& Administração, v. } 7, \mathrm{n} \text {. } \\
1,2008 \text {. }\end{array}$ & $\begin{array}{l}\text { Santos questiona: "Como não tratar, dentro de uma única } \\
\text { lógica de classificação, um pequeno conjunto de retratos } \\
\text { emoldurados de pesquisadores, encontrado em um } \\
\text { arquivo de cientista?" (p. 23) }\end{array}$ \\
\hline $\begin{array}{l}\text { SILVA, Armando B. Malheiro } \\
\text { da. } \\
\text { Abordagem aos arquivos } \\
\text { familiares e pessoais como } \\
\text { sistemas de informação. v. 3, n. 1- } \\
\text { 2, jan./dez. 2004. }\end{array}$ & $\begin{array}{l}\text { Silva assinala uma outra funcionalidade da fotografia em } \\
\text { arquivos pessoais: } \\
\text { "No momento inicial do trabalho de estudo e } \\
\text { disponibilização ao acesso público, é obrigatória uma } \\
\text { reportagem fotográfica completa do estado da } \\
\text { documentação, partindo-se de imagens de conjunto (do } \\
\text { mobiliário, ou dos recipientes onde foram encontrados os } \\
\text { documentos) até imagens de pormenor (para cada } \\
\text { dossier e documentos individualizados)." (p. 36) } \\
\text { Adverte também sobre ser "inevitável encontrar uma } \\
\text { tipologia documental diversificadíssima" e, entre as } \\
\text { citadas, menciona as fotografias, e acrescenta "que faz } \\
\text { parte de um único e polifacetado sistema" }\end{array}$ \\
\hline
\end{tabular}

Fonte: Elaborado pelas autoras com base na revisão bibliográfica (2020)

Nos 26 artigos que enfocam algum campo empírico, os 11 que mencionam a fotografia o fazem com níveis diferentes de detalhamento. Na maioria das vezes, em 6 textos (55\%), isso acontece quando é descrito do que se constitui o acervo, e eles somente mencionam que existem fotografias, e, em alguns casos, a quantificação. Em outros dois artigos, são abordados os usos dos documentos fotográficos do acervo, descrevendo a vida do titular por meio das fotografias. Em um deles é destacada a relação "da vida do ilustre com os documentos de arquivo" (MOSTAFA; ROMÃO, 2013, p. 37). Os outros três textos relatam o tratamento técnico que é dado às fotografias do acervo em foco. Destes três, em dois são aludidas questões quanto aos níveis de descrição na hierarquia do acervo. É descrito que as fotografias formam uma série própria (série Fotografias) e no outro "foram tratados de uma maneira especial: foram classificados nas mesmas subdivisões dos demais documentos; cada foto recebeu um número de registro que acompanha a sigla do arquivo e o número do álbum” (MELO, 2014, p. 205). Esse último modelo, aparentemente, refere-se a um tratamento técnico mais orgânico, pois dá a entender que está procedendo a uma organização sem separar os documentos por gênero. Apesar disso, não detalha a ponto de possibilitar essa inferência.

Quanto aos resultados, em relação às fotografias, são, na maior parte das vezes, inconclusivos, como já foi apresentado nas categorias anteriores sobre as formas em que o assunto aparece nos artigos, pois nem todos apresentam relatos de casos já concluídos, apontando apenas resultados parciais. 

periódicos da Ciência da Informação e Arquivologia

Pode-se constatar, com base nesta análise, que, em poucos casos, as fotografias são mencionadas nos arquivos pessoais, o que evidencia a necessidade de estudos aprofundando o tema. Menos de $25 \%$ dos 65 artigos - levantados sobre arquivos pessoais na base de dados Brapci - debruçam-se sobre o tratamento de documentos fotográficos em algum nível de detalhamento. Apenas 15 artigos, em 40 anos de publicações em periódicos que abordam o tema, é de uma escassez muito expressiva na literatura.

Um texto importante para o escopo da pesquisa, por unir os dois assuntos, não apareceu nos resultados da busca, por ter sido publicado em uma revista que não consta da Base Brapci, a Revista História, Ciências, Saúde - Manguinhos. Trata-se do texto de Aline Lacerda (2009, p. 117) sobre o arquivo pessoal de Carlos Chagas. Sua questão central "não tem como foco uma análise do arquivo de Carlos Chagas como um todo, mas incide sobre a documentação de caráter visual - notadamente fotográfica - integrante desse arquivo".

Sua importância está em apresentar uma proposta de organização de um arquivo pessoal usando um método funcional, em substituição ao anteriormente utilizado no acervo, baseado em temas, substituindo também o tratamento específico por suporte documental, muito comum de ser aplicado ao material iconográfico, na maioria dos arquivos. A autora afirma que, em acervos iconográficos, predomina a regra de separar esse material do restante do acervo, não apenas fisicamente, mas também com arranjo e descrições distintos, o que ocasiona a perda de significado no contexto do conjunto. E acrescenta que o tratamento de qualquer acervo usando a abordagem contextual "objetiva ultrapassar a força dos conteúdos dos documentos e moverse em direção às razões e circunstâncias de sua existência e os sentidos de sua produção" (LACERDA, 2009, p. 124). 


\section{Conclusão}

$\mathrm{Na}$ época atual, a grande maioria dos acervos pessoais, se não todos, contém documentos fotográficos, sejam eles em suporte papel ou em meio digital. O que se pode perceber é que, apesar disso, essa realidade não vem sendo acompanhada pela literatura de artigos de periódicos, em especial nos títulos brasileiros, da Arquivologia e da Ciência da Informação, disponíveis. No decorrer dos anos, nota-se um aumento significativo da bibliografia sobre arquivos pessoais, o mesmo acontecendo em relação à literatura sobre fotografias em arquivos, porém o campo de interseção entre os dois temas é quase inexistente.

$\mathrm{Na}$ literatura de arquivos pessoais, as abordagens sobre as fotografias são muito incipientes. Além disso, poucos autores mencionam a existência desses registros nos acervos ou os apresentam de forma superficial.

É consenso na área da Arquivologia o fato de os arquivos pessoais terem sido relegados a segundo plano em relação aos arquivos institucionais, o que também fica claro, a partir da análise da evolução da produção bibliográfica sobre o assunto, ao longo do tempo. Autores que se dedicaram a atuar e/ou desenvolver pesquisas na área dos arquivos pessoais, tais como Bellotto (1998), Camargo (2008), Cook (1998) e Thomassen (2012), entre outros, demonstram que esses arquivos apresentam características próprias dos demais. Além disso, os registros têm importância no que diz respeito aos valores informativo e probatório, registram atividades da vida humana, sejam organizacionais ou individuais, e partem de um contexto de produção e de acumulação. São fundamentais também para documentar a sociedade, algo que nem sempre é conseguido pelos arquivos institucionais.

A necessidade de que esses arquivos sejam tratados como tais, e não como coleções, objetiva garantir a manutenção deste contexto e da organicidade, nos arquivos pessoais. Esta manutenção da organicidade também faz com que o acervo esclareça sobre a pessoa, sua vida e sobre o próprio conjunto documental, o que contribui para a organização do acervo.

Nos artigos, são destacadas também a tipologia documental diversificada e a forma física e de registro, que normalmente são encontradas nos arquivos pessoais, e as fotografias, entre outros gêneros, são citadas por vários autores. Porém, como documentos gerados da atividade quotidiana do indivíduo, complementam outros documentos produzidos por ele em suas ações. Como complementam documentos de suportes e gêneros diferentes, deve-se ter o cuidado com a preservação dos vários exemplares, proporcionando a separação física e o 
adequado condicionamento. Entretanto, a união lógica e intelectual deve ser assegurada, a fim de se manter a organicidade.

Quando esses acervos são desmembrados e separados entre setores de uma instituição, utilizando critérios de gênero ou de suporte, às vezes distribuídos até mesmo entre instituições diferentes, perde-se ou dificulta-se a oportunidade de se ter uma visão geral do produtor do acervo.

Entre os textos que abordam a fotografia, a maioria são relatos de caso, restringem-se à mencionar o fato de o acervo conter este gênero documental, descrevendo como o acervo se constitui, em alguns casos, a sua quantificação, em outros, destaca-se a importância das informações que as fotografias contêm. Portanto, os artigos, além de serem escassos, não explicitam como se dá o tratamento técnico e se a relação orgânica é respeitada. Em apenas um relato, fica claro que as fotografias foram tratadas de forma integrada ao acervo. Quando os artigos mencionam o documento fotográfico de uma maneira geral, sem estar se referindo a um acervo em especial, destacam a importância deste documento e de sua inserção no conjunto documental.

O que se pode constatar é a grande lacuna e a necessidade urgente de uma discussão profunda sobre o assunto, e do desenvolvimento de pesquisas, gerando produção intelectual e transformando a situação que se apresenta. $\mathrm{O}$ tema também carece de produção bibliográfica que possa servir de orientação para o tratamento técnico das fotografias pertencentes aos arquivos pessoais, sendo organizadas de forma a atender às suas especificidades. Esperamos que esses estudos possam contribuir com a sociedade, na tarefa de registrar e preservar sua memória e cultura. 


\section{Referências}

ABREU, Jorge Phelipe Lira de. Aprender a ler entre bits: autenticidade em arquivos pessoais digitais. Acervo - Revista do Arquivo Nacional, Rio de Janeiro, n. 2, v. 29, p. 133-142, 2016. Disponível em: http://www.brapci.inf.br/index.php/res/v/42455. Acesso em: 27 dez. 2018.

ARTIÈRES, Philippe. Arquivar a própria vida. Revista Estudos Históricos, Rio de Janeiro, v. 11, n. 21, p. 09-34, 1998.

BELLOTO, Heloísa Liberalli. Arquivos pessoais em face da teoria arquivística tradicional: debate com Terry Cook. Revista Estudos Históricos, Rio de Janeiro, v. 11, n. 21, p. 201-208, 1998.

BARROS, Myriam Moraes Lins de; STROZENBERG, Ilana. Álbum de família. Rio de Janeiro: Comunicação Contemporânea, 1992.

CALLIGARIS, Contardo. Verdade de autobiografias e diários íntimos. Revista Estudos Históricos, Rio de Janeiro, v. 11, n .21, p. 43-58, 1998.

CAMARGO, Ana Maria de Almeida. Sobre arquivos pessoais. Arquivo \& Administração, Rio de Janeiro, n. 2, v. 7, 2008. Disponível em: http://www.brapci.inf.br/index.php/res/v/51291. Acesso em: 4 dez. 2018.

CARVALHO, Flávia Barros Fernandes; MAIA, Manuela Eugênio; OLIVEIRA, Bernardina Maria Juvenal Freire. Difusão cultural no arquivo Afonso Pereira: o teatro do estudante da Paraíba e sua construção expográfica. Ponto de Acesso, Salvador, n. 3, v. 11, p. 73-90, 2017. Disponível em: http://www.brapci.inf.br/index.php/res/v/81781. Acesso em: 26 dez. 2018.

COOK, Terry. Arquivos pessoais e arquivos institucionais: para um entendimento arquivístico comum da formação da memória em um mundo pós-moderno. Revista Estudos Históricos, Rio de Janeiro, v. 11, n. 21, p. 129-149, 1998.

DUCROT, Ariane. A classificação dos arquivos pessoais e familiares. Revista Estudos Históricos, Rio de Janeiro, v. 11, n. 21, p. 151-168, 1998.

FRAIZ, Priscila. A dimensão autobiográfica dos arquivos pessoais: o arquivo de Gustavo Capanema. Revista Estudos Históricos, Rio de Janeiro, v. 11, n. 21, p. 59-87, 1998.

GOMES, Michele de Almeida; SILVA, Maria Celina de Mello e. Objetos tridimensionais em arquivos pessoais de cientistas. Arquivo \& Administração, Rio de Janeiro, n. 1, v. 10, 2011.

GONÇALVES, Eveline Filgueiras; ALBUQUERQUE, Maria Elisabeth Baltar Carneiro de. Arquivo pessoal e fotografias: lugar de construção fotoaubiográfica. Pesquisa Brasileira em Ciência da Informação e Biblioteconomia, João Pessoa, n. 1, v. 10, 2015. Disponível em: http://www.brapci.inf.br/index.php/res/v/29635. Acesso em: 5 dez. 2018.

HEYMANN, Luciana Quillet. Indivíduo, Memória e resíduo histórico: uma reflexão sobre arquivos pessoais e o caso Filinto Muller. Revista Estudos Históricos, Rio de Janeiro, v. 10, n. 19, p. 41-66, 1997. 
LACERDA, Aline Lopes de. Fotografia e valor documentário: o arquivo de Carlos Chagas.

Hist. cienc. saude-Manguinhos, Rio de Janeiro, v. 16, supl. 1, p. 115-138, jul. 2009.

Disponível em: http://www.scielo.br/scielo.php?script=sci_arttext\&pid=S010459702009000500007\&lng=pt\&nrm=iso. Acesso em: 14 jul. 2020.

LEITE, Miriam Moreira. Retratos de família: leitura da fotografia histórica. São Paulo: EDUSP, 2001.

MARIZ, A. C. A.; CORDEIRO, R. I. N. A importância do contexto para as fotografias de arquivos: uma análise de literatura. In: ENCONTRO NACIONAL DE PESQUISA EM CIÊNCIA DA INFORMAÇÃO,19., 2018, Londrina. Anais eletrônicos [...]. Londrina: PPGCI: Ancib, 2018. Disponível em: http://enancib.marilia.unesp.br/index.php/XIXENANCIB/xixenancib/schedConf/presentations . Acesso em: 15 jul.2020.

MELO, Jonas Ferrigolo. Organização do arquivo pessoal e eclesiástico de Dom Ivo Lorscheiter. BIBLOS: Revista do Instituto de Ciências Humanas e da Informação, Rio Grande, v. 28, n. 3, p. 203-206, 2014. Disponível em: http://www.brapci.inf.br/index.php/res/v/24127. Acesso em: 26 dez. 2018.

MILLAR, Laura. Touchstones: considering the relationship between memory and archives. Archivaria, Ottawa, v. 61, p. 105-126, Spring. 2006.

MOSTAFA, Solange Puntel; ROMÃO, Lucília Maria de Sousa. Além de nós... evidências da multiplicidade. Informação \& Sociedade: Estudos, João Pessoa, v. 23, n. 3, 2013. Disponível em: http://www.brapci.inf.br/index.php/res/v/91377. Acesso em: $31 \mathrm{dez} .2018$.

OLIVEIRA, Lucia Maria Velloso de. Arquivos pessoais e documentos digitais: uma reflexão em tomo de contradições. Arquivo \& Administração, Rio de Janeiro, v. 7, n. 1, 2008. Disponível em: http://www.brapci.inf.br/index.php/res/v/51434. Acesso em: 4 dez. 2018.

OLIVEIRA, L. M. V. Descrição arquivística e os arquivos pessoais: conhecer os arquivos pessoais para compreender a sociedade. Arquivo \& Administração, Rio de Janeiro, v. 12, n. 2, 2013. Disponível em: http://hdl.handle.net/20.500.11959/brapci/50372. Acesso em: 3 dez. 2018.

SANTOS, P. R. E. A ciência, os cientistas e os seus arquivos. Arquivo \& Administração, Rio de Janeiro, v. 7, n. 1, 2008a. Disponível em: http://hdl.handle.net/20.500.11959/brapci/51419. Acesso em: 2 jan. 2019.

SANTOS, Vanderlei Batista. Gestão de Arquivos Pessoais. Arquivística.net, Rio de Janeiro, v. 4, n. 1, p. 62-80, jan./jul. 2008b.

SCHELLENBERG, Theodore Roosevelt. Arquivos modernos: princípios e técnicas. Rio de Janeiro: FGV, 1973, 345p.

SILVA, Ana Cláudia Felipe da; CORDEIRO, Rosa Inês de Novais. Álbuns de família: um estudo sobre as suas características como registro privado e acesso público nas unidades de memória e informação. In: ENCONTRO NACIONAL DE PESQUISA EM CIÊNCIA DA INFORMAÇÃO, 17., 2016, Salvador. Anais [...]. Salvador: UFBA, 2016. 
SILVA, Armando Malheiro. Abordagem aos arquivos familiares e pessoais como sistemas de informação. Arquivo \& Administração, Rio de Janeiro, v. 3, n. 1/2, 2004. Disponível em: http://hdl.handle.net/20.500.11959/brapci/31868. Acesso em: 1 jan. 2019.

SILVA, Armando. Álbum de família: a imagem de nós mesmos. São Paulo: Sesc/Senac, 2008 .

SILVA, Maria Celina Soares de Mello e. Configuração da informação em documentos de ciência e tecnologia: estudo tipológico no arquivo pessoal do físico Bernhard Gross.

Perspectivas em Ciência da Informação, Belo Horizonte, v. 18, n. 3, p. 160-174, 2013. Disponível em: http://www.brapci.inf.br/index.php/res/v/36090. Acesso em: 1 jan. 2019.

SOBRAL, Camilla Campoi de; MACÊDO, Patrícia Ladeira Penna. Antropologia das emoções em arquivos pessoais: a interdisciplinaridade como instrumento. Informação Arquivística, Rio de Janeiro, v. 6, n. 2, 2017. Disponível em:

http://www.brapci.inf.br/index.php/res/v/93353. Acesso em: 2 jan. 2019.

THOMASSEN, Theo. Arquivistas e o desejo privado de ser ou não documentado. Arquivo \& Administração, Rio de Janeiro, v. 11, n. 2, 2012. Disponível em:

http://www.brapci.inf.br/index.php/res/v/50678. Acesso em: $31 \mathrm{dez} .2018$.

TOGNOLI, Natália B.; BARROS, Thiago Henrique Bragato. As implicações teóricas dos arquivos pessoais: elementos conceituais. Ponto de Acesso, Salvador, v. 5, n. 1, p. 66-84, 2011. Disponível em: http://www.brapci.inf.br/index.php/res/v/68027. Acesso em: 1 jan. 2019.

TRANCOSO, Marcia Cristina Duarte; SILVA, Maria Celina Soares de Mello e. Identificação de tipos documentais em arquivos pessoais: estudo no arquivo do físico Joaquim da Costa Ribeiro. Arquivo \& Administração, Rio de Janeiro, v. 12, n. 2, 2013. Disponível em: http://www.brapci.inf.br/index.php/res/v/50387. Acesso em: 20 ago. 2018.

VIANNA, Aurélio; LISSOVSKY, Maurício; SÁ, Paulo S. M. de. A vontade de guardar: lógica da acumulação em arquivos privados. Arquivo \& Administração, Rio de Janeiro, v. 10-14, n. 2, 1986. 